\title{
The Role of Gender Power Imbalances in the Spread of HIV among Women in Intimate Relationships: Guidelines for Social Work Practice
}

\author{
Goitseone Emelda Leburu-Masigo* and Nathaniel Phuti Kgadima*
}

\author{
Department of Social Work, Winnie Madikizela-Mandela Building, Office 5-29, South Africa
}

\begin{abstract}
Gender power imbalances and HIV are concerns that affect women globally. Social workers are ethically committed to help people affected with HIV and thereby promote gender equality. Although the literature has documented the nexus between gender imbalances and HIV, scant research explores these problems concurrently within the social work profession. Drawing on the resource theory and gender and power theory, this article undertook a qualitative exploratory to gain insights into women's perspectives on gender power imbalances as a risk factor for HIV transmission in rural communities of Ngaka Modiri Molema District, North West Province. Purposive sampling was used to recruit participants while data was collected through semi-structured interviews. The findings demonstrate that unequal power relations between men and women in intimate relationships negatively affect women's lives in diverse ways. This gendered impact of HIV infections for women remains intact due to the rooted gender norms that limit their ability to protect themselves against risky sexual behavior by their male partners. Disclosure of one's status remains a complex stigma attached to HIV. Social work empowerment interventions that seek to enhance equality in intimate relationships are recommended.
\end{abstract}

Keywords: Gender power imbalances, intimate relationships, HIV, women, social work.

\section{INTRODUCTION AND BACKGROUND INFOR- MATION}

Human Immunodeficiency Virus (HIV) and gender power imbalances are critical issues confronting intimate relationships globally. Hatcher, Tsai and Kumbakumba (2012) assert that gender-based power imbalances within intimate relationships negatively affect women's sexual, reproductive, physical, and mental health. An increasing body of evidence demonstrates how unequal levels of power between men and women in intimate relationships prevent women, including women living with HIV, from making informed decisions regarding their sexual and reproductive health (Fransisco, Abramsky, Kiss, Michau, Musuya, Kerrigans, Kaye \& Watt, 2013; Shattuck, Burke, Ramirez, Succop, Costenbader, Attafuah, Mndeme, Mbwambo, \& Guest, 2013; Robinson, Naraimhan, Amin, Morse, Beres, Yeh, 2017; Closson, Ndungu, Beksinska, Ogilvie, Dietrich, Gadermann, Gibbs, Nduna, Smit, Gray, \& Kaida, 2019).

Women seem to be affected more by HIV transmission globally (Brawner, Teitelman, Bevilacqua \& Jemmott, 2013). During the 2016 United Nations Political Declaration on Ending HIV and AIDS, countries made commitments for adolescent girls and women to reduce the number of new HIV infections

${ }^{*}$ Address correspondence to these authors at the Department of Social Work, Winnie Madikizela-Mandela Building, Office 5-29, South Africa; Tel: 012429 3805; E-mail: leburge@unisa.ac.za, kgadinp@unisa.ac.za from 390000 in 2015 to 100000 in 2020 and to ensure that $90 \%$ of young people have skills, knowledge, and capacity to protect themselves against HIV. However, the world is far from reaching the set target as the HIV and AIDS epidemic continues to be a significant public health problem globally for women. Globally, an estimated 36.7 million people were living with HIV in 2016; 34.5 million of the 36.7 million were women above the age of 15 years, 1.8 million were newly infected with HIV, and 1 million died because of AIDS related illness (Klass, Thuapagale-Tshweneagae, Makua, 2018). Of the total number of people living with HIV and AIDS globally, women account for just over half (about 51 percent) of new infections each year (Harrison, 2014), with adolescent girls and young women most affected by HIV (United AIDS, 2019).

Southern Africa has the highest prevalence of HIV and AIDS globally (Rwafa, Shamu \& Christofides, 2019). Botswana occupies the first spot with an estimated $60 \%$ of the population infected (Becker, HoFoster, Poku, Marobela, Mehta, Cao, Yang, Blank, Dipatane, Moeng, Molebatsi, Eisenberg, Barg, Blank, Opondo, \& Yang, 2019:1566). The total number of people living with HIV in South Africa increased from 4.25 million in 2002 to 7.52 million by 2018 . For 2018 , an estimated $13,1 \%$ of the total population was HIV positive, and approximately one-fifth of South African women aged between 15 and 49 years were HIV positive (Statistics South Africa, 2017). Since the discovery of the HIV pandemic, the issue of power differences between men and women in HIV has taken on a multifaceted status in addressing the pandemic. 
The gender differences between men and women regarding HIV have a cause-effect relationship on various factors such as transmission of the virus, gender divisions, cultural beliefs, and practices. Although serval factors have been associated with the transmission and spread of HIV, power differences and the dynamics are viewed as significant contributors to the spread of HIV among women. Moreover, the existing power imbalances between men and women make women susceptible to contracting HIV. Consequently, the increasing statistics of HIV suggest a need to investigate the complex interplay between power and the spread of HIV.

The high levels of HIV prevalence among women in Southern Africa reflect deep-rooted social and gender inequalities (Rwafa et al., 2019) and harmful gender norms (USAIDS, 2017). Gender and power imbalances between men and women contribute to this risk (World Health Organisation, 2012; Harrison, 2014). The gender inequalities and men's perceived sexual and economic superiority over women consequently have significant health implications. These perceptions and imbalances are contributory factors to HIV infection (Klass et al., 2018). As a result, most women have limited capacity to exercise their human rights, protect themselves, and control their sexuality. This power imbalance prevents women living with HIV from achieving optimal sexual health and making informed decisions regarding their sexual reproductive health (Robinson et al., 2017).

The USAIDS (2012) reports that gender inequality drives the HIV epidemic and devoted the issue to discussing the gender-related risk factors that influence HIV infection among women. Evidence from multiple settings across sub-Saharan Africa suggests several ways in which gender inequalities affect women's disproportionate exposure to the risk of HIV infection (Closson et al., 2020). First, women's unequal social, economic, and political status places them at an inherent disadvantage in many aspects of life. Second, women's unequal power in intimate relationships across many contexts remains uncodified constraints regarding women's ability to negotiate a relationship, family, and household level.

It has been argued that social work practice in Africa fails to tackle these social problems because it deploys skills and strategies deeply rooted in western standards and principles (Rwomire, 2012; Chadambuka \& Warria, 2019). Conversely, Baffoe and Dako-Gyeke (2013) argue that social work education that incorporates gender studies in Africa is largely dominated by western principles. Thus, most conventional social work practice skills and strategies have limited impact on the specific social needs and problems in developing countries such as South Africa (Rwomire, 2012; Chadambuka \& Warria, 2019).

Social work is at the forefront of professions that address the need for healthy relationships and promote enhanced social functioning among people (O'Leary, Tsui \& Ruch, 2013). Despite this mandate, there seems to be scant research from the social work fraternity on how gender power imbalances contribute to the spread of HIV infection among women. Kiboro, Gakuru, Misaro and Mwangi, (2014) concede that although several approaches have been incorporated into the gender mainstreaming programs, it seems to have offered minimal attention to the possible contributions from the social work profession. It is, therefore, clear that it would benefit the social work profession to gain more insight into the complex issues of power imbalances and HIV in intimate relationships. Likewise, the gender power imbalances associated with the magnitude of HIV among women demand urgent investigation and interrogation to curb the spread of the virus and improve the lives of women infected and affected with HIV.

Guided by the Resource Theory as well as the Theory of Gender and Power, this study sought to answer the following research questions:

Research Question 1: What is the role of gender power imbalances in the spread of HIV among women?

Research Question 2: How can social workers address gender power imbalances to curb the spread of HIV among women?

\section{PREVAILING SOCIAL NORMS AND TRADITIONAL VALUES THAT PERPETUATE POWER IMBALANCES}

The role of social norms, traditional values, and beliefs that perpetuate gender power imbalances and HIV cannot be ignored. Amidst varying interpretations, social norms essentially denote 'the informal, mostly unwritten, rules that define acceptable, appropriate, and obligatory actions in a given group or society (Piedalue, Gilbertson, Alexeyeff \& Klein,2020: 90). Although sexual behavior still differs according to various cultures across the continent (Rosenthal \& Levy, 2010), prevailing gender norms account for Africa's high HIV infection rates (Shattuck et al., 
2013:54). Therefore, to understand why the African continent is still disproportionately affected by HIV, the discussion on the prevailing social norms that may exacerbate this desperate state of affairs constitutes an important part of this study. Women generally still occupy a subordinate and submissive partner position, thus making them vulnerable to HIV transmission and acquisition. On the other hand, men still enjoy greater power than women, which is perpetuated by societal institutions and gender-based practices (Wamoyi, Ranganathan, Mugunga, \& Stöck, 2021). Traditional practices such as polygamous unions allow men to engage in multiple sexual partnerships.

Some cultures do not explicitly condemn extramarital affairs for men, while they explicitly discourage women from expressing their discomfort over such behaviors (Shattuck et al., 2013). For instance, men in Tanzania and Nigeria seek extra-marital sexual partners to boost their perceptions of manhood (Conserve, Sevilla, Mbwambo \& King, 2012). Similarly, studies in South Africa and neighboring Mozambique also found widespread gender inequalities in intimate relationships wherein women have limited power and control over their male partners' sexual behaviors (Bandali, 2012). Women in these two countries in the region, commonly shortened as SADC (South African Development Community), have limited voice in using condoms during sexual intimacy and using the theory of gender and power to investigate the phenomenon of marital rape and its association with HIV risk transmission and acquisition in Uganda. One of the study's key findings was that women's inferior economic position makes them rely on their financially empowered male partners, thus limiting their ability to negotiate safe sexual practices (Mengo, Okumu, Ombayo, Nahar, \& Small, 2019).

\section{CONCEPTUALISING GENDER AND POWER}

Two concepts are central to this study, namely gender and power. For this study, it is crucial how the two concepts of gender and power are defined. Gender is tricky as definitions vary across different social and cultural contexts (Levitt, 2019:276). Gender is often used interchangeably or, in some instances, confused with sex. In reality, gender and sex are different terms. Whereas sex denotes a biological characteristic related to sex genes, gender is a socially constructed identity (Sinacore, Durrani, \& Khayutin, 2021:1661). The term gender "includes the social norms, beliefs, practices, and structures that stipulate what is feminine, masculine, good parenting, queer, straight, proper behavior..." (Thurston, Tam, Dawson, Jackson, \& Kwok, 2016:696).

Simply put, "people are born female or male but learn to be girls and boys who then grow into women and men" (Bradbury-Jones, Appleton, Clark \& Paavilainen, 2019:470). These learned behaviors ultimately determine how individuals conduct themselves in society (Malik \& Dixit, 2017). This study adopts this understanding of gender to interrogate the power imbalances that accrue from such socialization to clarify the complexities of HIV infection and its spread amongst disempowered women.

Some authors associate gender with power (Brubaker, 2021). This association is important in understanding the role of gender power imbalances in the spread of HIV among women in intimate relationships. Power is an important aspect of any human relationship, and it affects various aspects of life. It is a profoundly complex element in any relationship, whether this is an intimate or sexual relationship (Halstead, De Santis \& Williams, 2016). Relational power, or one's authority in a relationship, can be understood in terms of one's ability to exercise influence over a partner's behavior and influence decisions in the relationship (Katz \& LaRose, 2019; Levitt, 2019). In the context of this study, the concept of power is used in terms of men's and women's control over decision-making in their intimate relationships.

\section{THEORETICAL UNDERPINNING}

The spread of HIV and AIDS has been rightfully phrased as the "sociological epidemic" by Lichtenstein and DeCoster (2014:140) because the power and capacity to distribute resources in society affect the social patterning of HIV and AIDS. Therefore, two theoretical frameworks were deemed relevant and appropriate to guide this study, namely, Resource Theory and Gender and Power Theory. The two theories are used in complementary ways rather than interchangeably to understand the dynamics in the spread of HIV in South Africa.

The Resource Theory suggests that the inherent inequalities in power is likely to be used by male partners as the ultimate resource to gain control if there is lack (real or perceived) of key resources such as income, educational attainment and occupational prestige. Generally, men in South Africa and elsewhere have a higher income, higher educational attainment, and hold more prestigious jobs than women (Basile, 
Hall, Mikel \& Walters, 2013). Proponents of resource theory further argue that social resource constraints and related social stress increase the risk of male dominance with the idea of a dominant sex role. Expectations (e.g., male as breadwinner) are violated by resource imbalances favoring female partners (Basile et al., 2013). Moreover, the resource theory contends that force and its threat can be used when other resources are unavailable or have proved ineffective. In other words, men with fewer resources outside the relationship, such as when facing unemployment or financial hardships, are more likely to use the threat of dominance to re-establish their control within the relationship (Lawson, 2012). Relationships in which power is equally balanced, partners are often hailed for embodying the principles of gender equality (Eaton \& Rose, 2011) and a relational ethic of mutuality (Lamb, 2010).

To respond to Research Question 1 above, the study also considered the Theory of Gender and Power. This theory was initially conceptualised by Raewyn Connel (1987) to explain how gender inequities and power imbalances manifest among women and men in relationships. This was later developed by Wingood and DiClemente (2000) to "highlight how gender-based inequities lead to greater exposure to HIV risk factors... among heterosexual women." (Hershow, Bhadra, Mai, Sripaipan, Ha, Go,2020). A considerable number of studies have drawn upon the Theory of Gender and Power to investigate how the manifestation of power within intimate relationships increases women's risk of HIV infection (Mengo et al., 2019; Groves, Reyes, Gebrekristos, Moodley, Maman, 2020; Closson et al. 2019; Wamoyi et al., 2021). This theory argues that unequal power based on gender generates sexual relationships that are unequal and weakens a woman's ability to control her health behavior (Mengo et al., 2019). With particular reference to women's risk for HIV and AIDS, this theory argues that power imbalances in intimate relationships largely disadvantage women during sexual interactions (Katz \& LaRose, 2019).

\section{RESEARCH METHODOLOGY}

A qualitative exploratory research design was used to explore the role of gender power imbalances in the spread of HIV among women. Participants were recruited from the two NGOs that render services to HIV and victims of violence in two villages. Purposive sampling was used to recruit and interview 21 eligible participants using semi-structured interviews. Data were analyzed thematically. Participants were women aged 21-40 years who had experienced any form of abuse from their male partners.

We obtained ethical clearance from the North-West University (Reference number: NWU-00235-14-A9). Additionally, verbal permission was sought and granted from the traditional leaders and center managers. Subsequently, briefing sessions were conducted at the selected NGOs, during which the participants were briefed about the aim of the study and procedures followed during data collection. The briefing sessions were followed by the participants completing consent forms. Interviews were audio-recorded and guided by semi-structured questions with open-ended questions. Interviews were conducted at the offices where participants worked and were conducted in Setswana, which is the participants' home language. This enabled the researcher to observe participants in their natural settings.

\section{FINDINGS}

Participants were invited to share their experiences on HIV risk factors in intimate relationships. They also offered their views on the experiences and connection between HIV and intimate partner violence and how HIV testing was negotiated in such relationships.

\section{THEME 1: HIV Risk Factors}

A diversity of factors seems to contribute to the spread of HIV among women in intimate relationships. The data indicate that most participants linked socioeconomic factors such as alcohol and poverty with the high rate of HIV infections in their communities. Under this theme, the three sub-themes of alcohol availability, economic dependence, and male dominance emanated.

\section{Subtheme 1.1: Alcohol}

Alcohol use increases the risk of acquiring and transmitting HIV (Wandera, Tumwesigye, Nankabirwa, Mafigiri, Parkes-Ratanshi, Kapiga, Hahn \& Sethi, 2017:276). The majority of participants indicated that alcohol is a risk factor for HIV. They indicated that alcohol is freely available, affordable to both the young and old in the community. The role of alcohol in the spread of HIV was highlighted by the majority of the participants and is encapsulated by the extracts below:

"I grew up in a family where both parents abused alcohol. They were drinking 
almost every day, and when they were drunk, my father would sometimes sleep with my mother in full view of us as children. We later learned from relatives after their passing on that both were HIV positive."

"At drinking places in most cases, young women who are cash-strapped often would sell themselves to men in exchange for alcohol."

"I was oblivious of what was going on because of my drinking stupor and only realized the following morning when I woke up next to this man who was last buying me alcohol drinks at the tavern. From that horrible incident, I decided never to go unaccompanied to a tavern anymore."

The participants' accounts support the assertion that alcohol intake is also gendered. According to Davis and Galvan (2012) alcohol problem or intake is most likely to expose women to HIV infections. One of the most sensible explanations is that alcohol intake impairs decision-making, resulting in riskier sexual behavior (Rehm, Probst, Shield, \& Shuper, 2017).

\section{Subtheme 1.2: Economic Dependence}

Resource Theory has also been employed to understand how economic inequalities expose women to the risk of HIV infections (Conroy, 2014). It was found that economic deprivation is one of the major challenges confronting women concerning the risk of HIV infections (Malik \& Dixit, 2017).

Similarly, the participants' experiences emerged that women with low economic status are more susceptible to HIV infection. The low economic status curtails women's ability to make sexual decisions. One participant said:

"Most poverty-stricken women tend to stay in a physically and sexually abusive relationships simply because of not having any other option."

Another participant added:

"Some women tend to settle for any subhuman treatment from their intimate male partners who provide financially, and if they get infected with the HIV, they blamed themselves."

The extracts demonstrate that women economically dependent on their intimate partners experience limitations in their negotiating power concerning sexual decisions and other related matters (Conroy, 2014). These women have no option but to agree religiously with the decisions of their male partners (Malik \& Dixit, 2017)

The Resource Theory also introduced the concept of positional power, which denotes one's capacity to influence their partner based on their economic resources (Körner \& Schütz 2021). Consequently, younger women become intimately involved with older men for material or financial gain, thus exposing themselves to risky sexual behavior (Rosenthal \& Levy, 2010:25; Mpondo, Ruiter, van den Borne, and Reddy, 2019), as the extract below bears testimony.

Due to lack of economic resources, participants referred to the fact that in the present times, older men enter relationships with young women so that they can overpower them very easily. The following except bears testimony to what was said:

"My younger niece of 16 years had an affair with a man thrice her age. When the relationship started, it was based on an exchange of very expensive gifts, outings, and money. After some time, the young woman wanted to quit on account that her schoolwork was suffering. The older man became violent and refused even to wear a condom. After the pregnancy and HIVpositive tests, the older man has since vanished. For fear of the family being ridiculed, the matter has never been reported to the police."

The participant's account highlights that age is another determinant of the differences in material or wealth accumulation between partners. Economic resources are still predominantly under the control of men, and this discrepancy may result in power imbalances and control over sexual decisions by the males (Malik \& Dixit, 2017). Therefore, women's lack of financial power forces them to partner with older men who demand unsafe sex with women in exchange for alcohol. Women's low economic status forces them to remain in abusive relationships where men control their sexual choices. Consequently, the low economic status 
forces women to persevere in unhealthy and abusive relationships while their male partners shower them with gifts or materials. Harrison (2014) confirms that well-known behavioral risk factors for HIV infection in women include unprotected sex, relationships with older male partners who are more likely to be HIV positive. Such men have greater power in a relationship and often limit women's ability to negotiate the terms of sexual engagement or prevention.

\section{THEME 2: Discussion on HIV}

Communication about HIV is a complex and difficult issue facing many couples in intimate relationships. This challenge might be perpetuated by the stigma and taboo attached to HIV. Arrey, Bilsen, Lacor, Deschepper (2015) pointed out that HIV is not yet socially accepted as a normal chronic disease like other diseases. The study shows that women take the leading role in initiating a conversation about HIV with their partners while their partners are reluctant to open up. Consistent with key assumptions of Resource Theory and Gender and Power and Gender Theory, the study also found that skewed power relations can also determine whether or not the male partners could initiate and discuss safer sex.

\section{Subtheme 2.1: Lack of Openness}

Discussion and open communication are key ingredients in an intimate relationship. Most importantly, it is desirable for the couples in intimate relationships to be aware of each other's HIV status. Researchers posit that knowing each other's HIV status can lead to engaging in safer sexual behaviour to eliminate HIV infection (Conserve et al., 2012). As the saying goes: "Knowledge is Power". In this study, participants believe men are reluctant to engage in conversations relating to HIV. The following excerpts reflect lack of awareness on the part of the participant's male partner about HIV and how it is transmitted:

"I have on several occasions tried to introduce the topic of HIV and AIDS to my intimate partner. For the years that we have been together, he has never shown any interest. He either keeps quiet or simply changes the subject. I buy relevant and easy-to-read books addressing the virus [HIV] but to no avail."

The study also established the gendered power dynamics, which may negatively impact the health of the women. Due to the lack of power, women are deprived of the right to negotiate matters about their sexual health, such as condoms, thus exposing themselves to a higher risk of HIV infections. The extracts below attest:

"With me, though my partner also shows reluctance, I have made it my business to educate him about HIV and AIDS, including the contracting of STIs. When he goes on work outings or even holidays without me, I make a point that I pack in his luggage bag some condoms. He does not personally articulate the subject of HIV and AIDS verbally but sometimes would come with a condom, implying that we should use it at that time. For me, this is a start, though a slow one."

"I have been legally married to my present husband for over ten years. In those years, I have never initiated any sexual activity, let alone suggest that we should practice safer sex. When I got married, I was taught by both the men and women elders that a man is the initiator of sex. You are frowned upon as being loose or morally wanting when you initiate a sexual activity as a woman. At the present moment, I am fully aware of the women my husband is having intimate relations with, yet bound by our cultural beliefs from confronting him about these extra-marital affairs."

"I do negotiate for condom use and safer sex with my partner some days, especially when I do not feel safe. Otherwise, he does not like the idea of even engaging in discussions about condom use. The practice is, however, not consistently followed based on disagreements and fights between us".

The final vignette here shows how the men generally refuse to engage in meaningful, non-coercive, and healthy conversations with regards intimacy:

"Our menfolk are reluctant to practice safe sex and even to go for tests, instead rely on the results of their women partners, who only get tested when they are pregnant and attending antenatal clinics. Some choose not to accept the positive 
status of their partners refusing to practice safer sex, a situation that results in reinfections."

Fear of violence can also hamper the women' decisions regarding their sexual health (Fransisco et al., 2013), such as whether to use a condom or not, as evident in the citation below:

"Our culture does not allow us to talk freely about sex and sexuality matters, either with our intimate male partners or even with our children. Culturally, the subject of sex and sexuality are taboo issues. On the other hand, bringing up the matter of safety in sexual relationships and sexual activity can even raise suspicion, which can lead to GBV [Gender Based Violence] against the woman, leading to more strains in the relationship."

The findings suggest that lack of openness, communication, and men's reluctance to fully engage in conversations regarding HIV are challenges prominent in intimate relationships. Arguably, it seems like the sole responsibility on sex talk and safe sex is put on women. Authors explain that their attitudes towards HIV can influence men's knowledge about their HIV status and how they communicate with their female partners (Conserve et al., 2012). However, other researchers argue that attitude towards HIV testing seems to be embroiled in gender connotations. For instance, in their study, Conserve et al. (2012) found that in Dar es Salaam (Tanzania), men generally do not fear disclosing their results to their female partners. In contrast, women expressed reservations about revealing their HIV status for fear of either being abandoned or abused by their male partners.

\section{Subtheme 2.2: Gendered Manifestations of HIV- Related Stigma}

More than 35 years after HIVIAIDS was first discovered and described, the fear of stigma from their partners, extended families, and community members is still an unfortunate reality for most individuals infected with HIV (Hershow et al., 2020).

The study provides insight into why a country such as South Africa still experiences high HIV infections and mortality rates, despite the increased availability of antiretroviral therapy (Njabanou, Atashili, Mbanya, Mbu, Ikomey, Kefie, Kinge, Etogo, Adimora \& Ndumbe, 2011).
Fear of stigmatization is a major justification for nondisclosure of HIV-positive status, which impedes the control of the pandemic (Tshisuyi, 2014) and is likely to influence the transmission of the virus (Akpa et al. 2011). This assertion was reflected in the experts below:

"The culture of silence in my community about one's HIV status prevents most women from accessing free treatment, which involves taking of antiretroviral therapy. A person can rather secretly access the help of traditional healers who themselves are not well informed about the virus, thus worsening their health condition."

This view is endorsed in the following vignette on the alarming death rate in the North West Province where the participant resides:

\begin{abstract}
"Almost every weekend, we bury people who die from the HIV and AIDs virus in great numbers, mostly women. Irrespective of these high death rates, disclosure about one's HIV status is still a secret, simply because of the stigma attached to the virus."
\end{abstract}

Issues of gendered morality and stigma regarding women's HIV status are still prevalent in many South African communities (Malik \& Dixit, 2017). Many communities still hold prejudicial beliefs that women bring HIV into the family. As a result, some women are reluctant to visit medical centers, thus, opting to devise alternative means such as visiting traditional healers secretly. The Joint United Nations Programme on HIV and AIDS describes HIV-related stigma as conceding that "stigma and discrimination could serve as major roadblocks to universal access to HIV prevention, treatment, care and support" (Panda, Das, Maruf \& Pahari, 2015).

\section{DISCUSSION}

This study sought to answer two research questions. The first research question was concerned with the role of gender power imbalances in the spread of HIV among women. The discussion is limited to the first question. The second question is responded to in the next section. Regarding the first question, the salient result is that unequal power relations between men and women exist to a greater extent in intimate 
relationships and affect women's lives in different ways, irrespective of one's socio-economic, cultural background, educational, and employment status. The findings established that alcohol abuse and availability contribute to the spread of HIV through unprotected sex between intimate partners.

Most women find out about their HIV-positive status when they realize that they are pregnant, while men are reluctant to test. The findings support Klass et al. (2018) view that HIV is prevalent among women of reproductive age. Furthermore, the findings confirm a study conducted by Lekalakala-Mokgele (2016), who established that South African men are less likely to go for HIV testing than women and are less likely to be aware of their status. This reluctance endangers their female partners, who may be less likely to use HIV prevention methods if unaware of their partners HIV positive status (Peacock, Weston, Evans, Daub \& Greig, 2008)

Findings confirmed that disclosing one's status is a complex issue that is often kept secret. This might be influenced by the stigma and discrimination attached to HIV, which inhibits many people from voluntary testing and accessing treatment. Subsequently, the study shows that men battle the most with denial, which puts them at greater risk of reinfection and spreading the virus to other partners. Instead of adhering to safe sex and treatment, they consult traditional healers whose knowledge of transmission and prevention of viral infection is sparse.

\section{IMPLICATIONS FOR SOCIAL WORK PRACTICE AND RECOMMENDATIONS}

Regarding the second question, the study sought to determine how social workers could address gender power imbalances to curb the spread of HIV among women. This study identified several implications that are central to the very existence of the social work profession. From its inception, social work has always been occupied with human rights, working on the side of social justice (Šadić, McPherson, Villarreal-Otálora, Bašić, 2020). The study confirms that the gendered impact of HIV infections for women remains intact due to the rooted gender norms that limit their ability to protect themselves against risky sexual behavior by their male partners. In other words, men still hold power that women are denied. It was, therefore, appropriate that the study suggest recommendations that address this power imbalance. The proposals relate to the social work practice as well as research.

\section{RECOMMENDATION FOR PRACTICE}

Women's educational attainment can arguably increase their access to resources and power in their intimate relationships. On the contrary, women with limited educational status and low income tend to be more vulnerable to risky sexual relationships (Mpondo et al., 2019).

Therefore, social work empowerment interventions that seek to enhance women's equality in intimate relationships should be founded in improving women's access to informed education platforms.

Second, the social work interventions that aim to confront gender inequalities in intimate relationships to reduce levels of HIV risk behavior should engage both men and women equally in discussions about prevailing norms and their implications.

\section{RECOMMENDATION FOR RESEARCH}

Understanding the power dynamics emanating from gender norms and HIV is crucial in establishing relevant and effective programs. Therefore, this study calls for more studies on gender dynamics in intimate partner relationships. This study further submits that understanding gender could provide practitioners with insight into their clients' experiences.

\section{CONCLUSION}

This article explored and described the role of gender power imbalances in the spread of HIV among women. Gender power imbalances play a prominent role in the HIV epidemic in South Africa, where HIV infection rates are prevalent, especially among women. The relationship between these variables is complex, and they need to be interrogated further. The complexity is worsened by gender norms into which people are socialized. Women in their reproductive ages are negatively affected by the power inequities that make them vulnerable to HIV. Both women and men need to be prepared and supported in learning about HIV and the importance of balanced power in intimate relationships. It is important to create support networks that challenge gender power imbalances. The imbalances perpetuate stereotypic ideologies about women in the North West Province, as demonstrated in this study. This process may be facilitated through open and informal gatherings in the communities to reduce the stigma attached to HIV and improve communication skills and strategies in intimate relationships. Because of the limited nature of this 
study, it is recommended that further research be conducted in other settings (including various races) involving men and social workers.

\section{REFERENCES}

Akpa, O.M. Adeolu- Olaiya, Ouselgun-Odebiri, A \& Aganaba, D. 2011. HIV/AIDS-related stigma and access to HIV treatment by people living with HIVIAIDS: A case study of selected states in North-Western Nigeria. HIV/ AIDS Review10, 19-25. https://doi.org/10.1016/j.hivar.2010.12.004

Arrey, A. E., Bilsen, J., Lacor, P \& Deschepper, R. 2015. "It's My Secret": Fear of disclosure among Sub-Saharan African Migrant Women living with HIVIAIDS in Belgium. PLOS ONE 10(3):e0119653. https://doi.org/10.1371/journal.pone.0119653

Baffoe, M. \& Dako-Gyeke, M. (2013). Social problems and social work in Ghana: Implications for sustainable development. International Journal of Development and Sustainability, 2(1):347- 363.

Bandali, S., 2013. HIV risk assessment and risk reduction strategies in the context of prevailing gender norms in rural areas of Cabo Delgado, Mozambique. Journal of the International Association of Providers of AIDS Care (JIAPAC), 12(1), pp. 50-54. https://doi.org/10.1177/1545109712453937

Basile, KC, Hall, JE, Mikel, L \& Walters, ML (2013). Expanding resource and feminist-informed theory to explain intimate partner violence perpetration by court-ordered men. Violence against Women, 19(7), 848-80.

https://doi.org/10.1177/1077801213497105

Becker, T.D., Ho-Foster, A.R., Poku, O.B., Marobela, S., Mehta, H., Cao, D.T.X., Yang, L.S., Blank, L.I., Dipatane, V.I., Moeng, L.R. and Molebatsi, K., 2019. "It's when the trees blossom": Explanatory beliefs, stigma, and mental illness in the context of HIV in Botswana. Qualitative Health Research, 29(11), pp.1566-1580.

https://doi.org/10.1177/1049732319827523

Bradbury-Jones, C., Appleton, J. V., Clark, M., \& Paavilainen, E. 2019. A profile of gender-based violence research in Europe: Findings from a focused mapping review and synthesis. Trauma, Violence, \& Abuse, 20(4), 470-483. https://doi.org/10.1177/1524838017719234

Brawner, BM, Teitelman, A.M., Bevilacqua, AW \& Jemmott, LS, 2013. Personalized bio-behavioural HIV prevention for women and adolescent girls. Global Advances in Health and Medicine, 2(5), pp.100-108. https://doi.org/10.7453/gahmj.2013.059

Brubaker, SJ, 2021. Embracing and Expanding Feminist Theory: $(\mathrm{Re})$ conceptualizing Gender and Power. Violence against Women, 27(5), pp.717-726. https://doi.org/10.1177/1077801220958494

Chadambuka, C \& Warria, D. Hurt or Help? 2019. Understanding intimate partner violence in the context of social norms practiced in rural areas. Social Work Maatskaplike Werk, 55(3); 300-310.

https://doi.org/10.15270/55-3-741

Closson, K., Ndungu, J., Beksinska, M., Ogilvie, G., Dietrich, J.J., Gadermann, A., Gibbs, A., Nduna, M., Smit, J., Gray, G. \& Kaida, A., 2020. Gender, power, and health: Measuring and assessing sexual relationship power equity among young sub-Saharan African women and men: A systematic review. Trauma, Violence, \& Abuse, p.1524838020979676. https://doi.org/10.1177/1524838020979676

Conroy, AA, 2014. Gender, power, and intimate partner violence: a study on couples from rural Malawi. Journal of Interpersonal Violence, 29(5), pp. 866-888.

https://doi.org/10.1177/0886260513505907
Conserve, D., Sevilla, L., Mbwambo, J. \& King, G., 2013 Determinants of previous HIV testing and knowledge of partner's HIV status among men attending a voluntary counseling and testing clinic in Dar es Salaam, Tanzania. American Journal of Men's Health, 7(6), pp.450-460. https://doi.org/10.1177/1557988312468146

Davis, EM \& Galvan, FH, 2012. Alcohol use among HIV-positive Latinas and African American women. Affiliate, 27(4), pp.435-448. https://doi.org/10.1177/0886109912464535

Eaton, A. A., \& Rose, S. 2011. Has dating become more egalitarian? A 35-year review using sex roles. Sex Roles, 64, 843-62. https://doi.org/10.1007/s11199-011-9957-9

Francisco, L., Abramsky, T., Kiss, L., Michau, L., Musuya, T., Kerrigan, D., Kaye, D. \& Watts, C., 2013. Violence against women and HIV risk behaviours in Kampala, Uganda: baseline findings from the SASA! Study. Violence against Women, 19(7), pp.814-832. https://doi.org/10.1177/1077801213497557

Groves, AK, Reyes, HLM, Gebrekristos, LT, Moodley, D. \& Maman, S., 2020. Examining why age-disparate relationships influence unsafe sex postpartum among South African women: Relationship control and physical partner violence as explanatory mechanisms. Journal of Interpersonal Violence, p.0886260520944531. https://doi.org/10.1177/0886260520944531

Hatcher, A. M., Tsai, A.C \& Kumbakumba, E. 2012. Sexual relationship power and depression among HIV-infected women in rural Uganda. Plos One, 7(2); 1-7. https://doi.org/10.1371/journal.pone.0049821

Halstead, V., de Santis, J., \& Williams, J. 2016. Relationship power in the context of heterosexual intimate relationships: A conceptual development. Advances in Nursing Science, 39, E31-E43. https://doi.org/10.1097/ANS.0000000000000113

Harrison, A. 2014. HIV prevention and research considerations for women in Sub-Saharan Africa: Moving toward a biobehavioral prevention strategies. African Journal of Reproductive Health, 18(300):17-24.

Katz, J. \& Larose, J., 2019. Male partner contraceptive interference: Associations with destructive conflict and women's relational power. Violence against Women, 25(10), pp.1262-1278. https://doi.org/10.1177/1077801218818372

Kiboro, C.N., Gakuru, O.N., Misaro, J. and Mwangi, S.W., 2014. Role of social work in minimizing sexual and gender inequalities. Research on Humanities and Social Sciences, 4(14), pp.848.

Klass, N.E., Tshweneyagae, G., \& Makua, T.P. 2018. The role of gender in the spread of HIV and AIDS among farmworkers in South Africa. African Journal of Primary Health Care \& Family Medicine. 10(1), 2071-928. https://doi.org/10.4102/phcfm.v10i1.1668

Lamb, S. 2010. Toward a sexual ethics curriculum: Bringing philosophy and society to bear on individual development. Harvard Educational Review, 80(1), 81-106. https://doi.org/10.17763/haer.80.1.c104834k00552457

Lawson, J. 2012. Sociological Theories of Intimate Partner Violence. Journal of Human Behavior in the Social Environment, 22(5), 572-90. https://doi.org/10.1080/10911359.2011.598748

Lekalakala-Mokgele, E. 2016. Exploring gender perceptions of risk of HIV infection and related behaviour among elderly men and women and women of Ga-Rankuwa, Gauteng Province, South Africa. Journal of Social Aspects of HIVIAIDS, 13(1), 88-95. https://doi.org/10.1080/17290376.2016.1218790

Levitt, HM, 2019. A psychosocial genealogy of LGBTQ+ gender: An empirically based theory of gender and gender identity cultures. Psychology of Women Quarterly, 43(3), pp.275-297. https://doi.org/10.1177/0361684319834641 
Lichtenstein, B. \& Decoster, J., 2014. Lessons on stigma: Teaching about HIVIAIDS. Teaching Sociology, 42(2), pp.140-150. https://doi.org/10.1177/0092055X13510412

Malik, A. \& Dixit, S., 2017. Women Living with HIVIAIDS: Psychosocial challenges in the Indian context. Journal of Health Management, 19(3), pp.474-494. https://doi.org/10.1177/0972063416666347

Mengo, C., Okumu, M., Ombayo, B., Nahar, S. \& Small, E., 2019. Marital rape and HIV risk in Uganda: The impact of women's empowerment factors. Violence against Women, 25(15), pp.1783-1805. https://doi.org/10.1177/1077801218821444

Mpondo, F., Ruiter, RA, van den Borne, B. \& Reddy, PS, 2019. Intimate partner violence and its association with selfdetermination needs and gender-power constructs among rural South African women. Journal of Interpersonal Violence, 34(14), pp.2975-2995. https://doi.org/10.1177/0886260516664316

Njabanou, N.M., Atashili, J., Mbanya, D., Mbu, E.R., Ikomey, G.M., Kefie, C.A., Kinge, T.N., Etogo, D., Adimora, A.A. \& Ndumbe, P.M., 2013. Sexual behaviour of HIV-positive women in Cameroon. Journal of the International Association of Providers of AIDS Care (JIAPAC), 12(2), pp.98-102. https://doi.org/10.1177/1545109711421640

O'leary, P., Tsui, M \& Ruch, G. 2012. The Boundaries of the Social Work Relationship Revisited: Towards a Connected, Inclusive and Dynamic Conceptualisation, The British Journal of Social Work, Volume 43, Issue 1, February 2013, Pages 135-153. https://doi.org/10.1093/bjsw/bcr181

Panda, S., Das, R.S., Maruf, S.A. \& Pahari, S., 2015. Exploring stigma in low HIV prevalence settings in rural West Bengal, India: Identification of intervention considerations. Journal of Mixed Methods Research, 9(4), pp.362-385. https://doi.org/10.1177/1558689814535843

Piedalue, A., Gilbertson, A., Alexeyeff, K. \& Klein, E., 2020. Is gender-based violence a social norm? Rethinking power in a popular development intervention. Feminist Review, 126(1), pp. 89-105. https://doi.org/10.1177/0141778920944463

Peacock, D., Redpath, J., Weston, M., Evans, K., DAUB, A \& GREIG, A. 2008. Literature Review on Men, Gender, Health and HIV and AIDS in South Africa. Cape Town; Sonke Justice Network.

Rehm, J., Probst, C., Shield, K.D. \& Shuper, PA, 2017. Does alcohol use have a causal effect on HIV incidence and disease progression? A review of the literature and a modelling strategy for quantifying the effect. Population Health Metrics, 15(1), pp.1-7. https://doi.org/10.1186/s12963-017-0121-9

Robinson, J.L., Narasimhan, M., Amin, A., Beres, K.B., Yeh, P.T \& Kennedy, C.E. 2017. Interventions to address unequal gender and power relations and improve self-efficacy and empowerment for sexual reproductive health decision making for women living with HIV: A systematic review. PLoS One 12(8): e0180699.

https://doi.org/10.1371/journal.pone.0180699

Rosenthal, L. \& Levy, SR, 2010. Understanding women's risk for HIV infection using social dominance theory and the four bases of gendered power. Psychology of Women Quarterly, 34(1), pp.21-35.

https://doi.org/10.1111/j.1471-6402.2009.01538.x

Rafa, T., Shamu. S., \& Christofides, N. 2019. Relationship power and HIV serostatus: An analysis of their relationship among lowincome urban Zimbabwean postpartum women. BMC Public Health, 19(792). https://doi.org/10.1186/s12889-019-7137-y

Rwomire, A. 2012. "The role of social work in national development." Social Work and Society, 10 (1); 108-117.

Šadić, S., Mcpherson, J., Villarreal-Otálora, T., \& BAŠIĆ, S. 2020. Rights-based social work in Bosnia and Herzegovina: Validating tools for education and practice. International Social Work, $0(0): 1$ - 14. https://doi.org/10.1177/0020872820912310

Sinacore, A. L., Durrani, S., \& Khayutin, S. 2021. Men's Reflections on Their Experiences of Gender-Based Violence. Journal of Interpersonal Violence, 36(3-4), 1660-1681. https://doi.org/10.1177/0886260517742148

Statistics South Africa. 2017. Midyear population estimates. Pretoria: Statistics South Africa.

Tshisuyi, E. T. 2014. Disclosure of HIV positive status to sexual partners among pregnant women in health district of Botswana. Pretoria: University of Pretoria. (Master's thesis).

Thurston, W. E., Tam, D. M., Dawson, M., Jackson, M., \& Kwok, S. M. 2016. The intersection of gender and other social institutions in constructing gender-based violence in Guangzhou China. Journal of Interpersonal Violence, 31(4), 694-714. https://doi.org/10.1177/0886260514556109

UNAIDS. 2017. Women and girls and HIV. Geneva, Switzerland.

UNAIDS. 2019. Women and HIV: A spotlight on adolescent girls and young women. Geneva, Switzerland.

UNAIDS. 2012. Report on the global AIDS epidemic. Geneva, Switzerland.

Wamoyi, J., Ranganathan, M., Mugunga, S. \& Stöckl, H., 2021. Male and female conceptualizations of sexual harassment in Tanzania: the role of consent, male power, and social norms. Journal of interpersonal violence, p.08862605211028309. https://doi.org/10.1177/08862605211028309

Wandera, B., Tumwesigye, N.M., Nankabirwa, J.I., Mafigiri, D.K., Parkes-Ratanshi, R.M., Kapiga, S., Hahn, J. \& Sethi, A.K., 2017. Efficacy of a single, brief alcohol reduction intervention among men and women living with HIVIAIDS and using alcohol in Kampala, Uganda: A randomized trial. Journal of the International Association of Providers of AIDS Care (JIAPAC), 16(3), pp.276-285. https://doi.org/10.1177/2325957416649669

\section{https://doi.org/10.6000/1929-4409.2021.10.170}

(C) 2021 Leburu-Masigo and Kgadima; Licensee Lifescience Global.

This is an open access article licensed under the terms of the Creative Commons Attribution License (http://creativecommons.org/licenses/by/4.0/) which permits unrestricted use, distribution and reproduction in any medium, provided the work is properly cited. 